\title{
EDUCAÇÃO DO CAMPO E POLÍTICA EDUCACIONAL EM DEBATE: APONTAMENTOS SOBRE A FORMAÇÃO DA CLASSE TRABALHADORA RURAL NA ATUALIDADE
}

\author{
Adriana do Carmo de Jesus \\ Júlia Mazinini Rosa \\ Maria Cristina dos Santos Bezerra \\ UFSCar
}

\section{RESUMO}

O presente artigo busca realizar alguns apontamentos a respeito do projeto atual de educação que o Estado brasileiro vem destinando à população trabalhadora do campo, em resposta às demandas dos movimentos sociais ligados à questão agrária. A discussão é feita com base na análise de documentos oficiais norteadores da política educacional para o campo que estão hoje em vigor. Entende-se que as mudanças, ou adaptações, nos projetos de educação são determinadas pelo capital e se colocam no sentido de atender os interesses da classe dominante. Problematizarmos a armadilha ideológica existente na reivindicação da especificidade na educação do aluno do campo, pois se a formação oferecida à criança da classe trabalhadora além de "básica", ou seja, voltada para a qualificação para o mundo do trabalho, se constituir em uma formação específica, fragmentada, com adaptações curriculares que contemplem o cotidiano, a vida e o trabalho no campo, a escola da classe trabalhadora "se empobrece", visto que abre mão de garantir a criança seu direito de apropriar-se do conhecimento formal. Deste modo, buscamos alguns elementos para refletir a respeito do argumento que considera que a concepção hegemônica de educação do campo acaba por privar a criança do campo do melhor e mais elaborado conhecimento que a humanidade produziu e acumulou.

Palavras-chave: educação do campo; política educacional; trabalhadores do campo

\section{RURAL EDUCATION AND EDUCATIONAL POLICY ON DEBATE}

\begin{abstract}
This paper seeks to accomplish some notes about the current education project that the Brazilian government has devoted to rural working-class, in response to the demands of social movements related do struggle for the land. The discussion is based on analysis of official documents that guides the rural educational policy today. It is understood that changes or adaptations to education projects are determined by the capital and serves the interests of the ruling class. We discuss about the ideological trap existing in claiming of a specificity in rural education, as well as a fragmented curriculum with some adaptions that contemplates only everyday life knowledge. We defend that the minimum and "basic" education offered by the State impoverishes rural working-class children formation since relinquishes the child to ensure their right to appropriate formal knowledge. Thus, we seek some elements to reflect on the argument that considers the hegemonic conception of rural education ultimately deprive the child of rural areas better and more elaborate knowledge that humanity has produced and accumulated.
\end{abstract}

Keywords: rural education; educational policy; rural working-class 


\section{Introdução}

Neste início do século XXI, percebe-se que as publicações de documentos e legislação do Ministério da Educação (MEC) têm sinalizado mudanças de concepção para o Ensino Fundamental. Neste sentido, verifica-se que a legislação publicada na última década tem acompanhado as tendências educacionais mundiais (MARTINS e ARCE, 2007).

É o caso, por exemplo, da lei 11.274 de 06 de fevereiro de 2006 que dispõe sobre a ampliação do ensino fundamental de 8 para 9 anos e que tem suscitado muito debate. Para muitos se trata de uma estratégia de equalização cultural, que tem por objetivo principal aumentar os anos de permanência na escola para promover maiores oportunidades de aprendizado, para outros se trata de mudanças insuficientes para a melhora efetiva na qualidade de ensino. O fato é que os documentos oficiais do MEC têm apontado grandes mudanças na concepção e na organização da educação básica no país, como sinalizam Martins e Arce (2007)

[...] Verifica-se portanto que vivemos um momento com anúncios de profundas mudanças no âmbito da educação básica obrigatória, se, é claro, a assunção do ensino fundamental de nove anos não se configurar como medida meramente administrativa (MARTINS e ARCE, 2007, p.39).

Assim, de modo inerente às mudanças postas, surgem diversos questionamentos em relação ao papel da educação escolar na vida do indivíduo e, sobretudo, em relação ao sujeito da educação escolar, o aluno. No que concerne à escola do campo, as questões suscitadas rementem ao contexto do campo.

Parte-se do pressuposto que na sociedade capitalista a escola pública adquiriu um caráter indispensável para a manutenção do estado das coisas, no sentido de garantir o processo de transmissão e difusão da ideologia da classe dominante e a formação da classe trabalhadora (SAVIANI, 2009, p. 24); há de se considerar também, que o nível de desenvolvimento atingido pela sociedade contemporânea, e em especial a brasileira, estabelece a exigência de um acervo mínimo de conhecimentos para que o indivíduo possa ser um cidadão. Tal formação se dá por meio da transmissão de "saberes", sobretudo com o desenvolvimento de habilidades básicas, como os processos de leitura e escrita e o domínio da matemática elementar, habilidades estas que são fundamentais para o ingresso da juventude no mercado de trabalho.

Entende-se que as mudanças, ou melhor, as adaptações nos projetos de educação na sociedade contemporânea, na qual incluímos os projetos de educação do campo, são determinadas pelo capital e se colocam no sentido de atender os interesses da classe dominante.

Nesta perspectiva, Pistrak (2000), pedagogo da Revolução Russa, nos mostra que a escola pode estar intimamente vinculada ao interesse de classe e aponta que a burguesia sempre esteve à frente do sistema de ensino defendendo seus interesses, em detrimento da classe trabalhadora. Mas, para o autor a escola pode assumir grande relevância nos processos revolucionários, sendo que podemos pensar "a escola como a arma ideológica da mudança, da revolução" (PISTRAK, 2000, p. 30). Da obra Fundamentos da Escola do Trabalho, destacamos: 
A escola sempre foi uma arma nas mãos das classes dirigentes. Mas estas não tinham nenhum interesse em revelar o caráter de classe da escola: as classes dirigentes não passavam de uma minoria, uma pequena minoria, subordinando a maioria a seus interesses, e é por isso que se esforçavam para mascarar a natureza de classe da escola, evitando colaborar na destruição de sua própria dominação (PISTRAK, 2000, p. 30).

\section{A respeito do projeto hegemônico de educação do campo na atualidade}

As articulações dos movimentos sociais nas últimas décadas possibilitaram o surgimento de algumas concepções de educação voltadas ao trabalhador do campo. Tais concepções reivindicavam que projetos educacionais fossem pensados, organizados e desenvolvidos com a participação dos sujeitos do campo, de modo a atender as necessidades do homem que vive "no" e "do" campo.

O Movimento por uma Educação do Campo é o movimento de luta por educação em áreas rurais mais importante existente na atualidade. Surgiu na década de 1990, inicialmente, de dentro dos movimentos sociais de luta pela terra, em especial o MST. Os primeiros eventos ${ }^{1}$ de amplitude nacional desta organização foram articulados entre movimentos sociais ligados à questão agrária, intelectuais e órgãos como CNBB, UNESCO e UNICEF. Dali organizou-se uma Articulação Nacional por uma Educação do Campo, com sede em Brasília e diversas reuniões que deram origem a ações, como a produção de livros de divulgação sobre a proposta educacional para o campo (ARROYO, FERNANDES, 1999, p. 8). As concepções deste movimento estão presentes em uma coleção de cadernos Por Uma Educação Básica do Campo (KOLLING et al. 1999; ARROYO, FERNANDES, 1999; BENJAMIN, CALDART, 2000; KOLLING et al. 2002; MOLINA, JESUS, 2004), além de diversos artigos destes autores. Há, além dos cadernos, outras referências importantes, por exemplo, os Cadernos Didáticos sobre Educação do Campo (TAFFAREL et al., 2010) e o Dicionário da Educação do Campo (CALDART et al., 2012).

Como lembram Hidalgo e Mello (2012, p. 1), as propostas de organização da educação do campo são contraditórias, pois apresentam elementos alinhados aos interesses dos trabalhadores do campo assim como convergem para os interesses do capital, em detrimento das possibilidades de formação e de protagonismo dos primeiros. Não há espaço neste artigo para nos alongarmos na descrição da história do Movimento por uma Educação do Campo em toda sua complexidade e suas contradições. Entretanto, é importante mencionar que a bandeira de luta pela educação que nasceu de dentro do movimento social passou a ter relação com a política educacional no Brasil durante os governos do Partido dos Trabalhadores. Mesmo porque uma das reivindicações do Movimento é por políticas públicas voltadas à população do campo. Embora Caldart $(2009$, p. 50) afirme que a educação do campo ainda não tenha se tornado política pública (e com isso a autora quer dizer que as reivindicações dos movimentos sociais não foram plenamente atendidas pelo Estado, com o que concordamos), algumas das principais concepções do Movimento estão presentes em documentos oficiais da política educacional voltada para o campo, como as Referências que estabelecem uma política nacional de educação do campo, (BRASIL, 2003) e as Diretrizes Operacionais para a Educação Básica nas Escolas do Campo (BRASIL, 2002). Sendo assim, há um projeto educacional para o campo em vigor que está fundamentado em concepções educacionais que estão 
diretamente relacionadas à pedagogia, bem como aquelas que, em sentido mais amplo, estão sempre relacionadas à educação: concepções de sociedade, de homem, de escola e também do que seria uma verdadeira transformação social.

As concepções educacionais do Movimento são foco de intenso debate acadêmico, existindo divergências até mesmo entre os teóricos do próprio Movimento. A coleção de cadernos Por Uma Educação Básica do Campo tem sofrido diversas críticas em virtude de sua interpretação da intensa desigualdade característica de áreas rurais centralizada na questão da identidade do sujeito do campo em detrimento da questão da luta de classes. Esta inclinação às ideias multiculturalistas seria o fundamento da defesa do Movimento de uma educação específica para o campo, o que o faria afastar-se da referência de uma educação unitária e universal, tendo como protagonista toda a classe trabalhadora, sendo ela rural ou urbana.

Em resposta a essas críticas, Caldart (2009, p. 42) afirma agora que o Movimento não defende uma educação específica para o campo de modo a perder de vista a perspectiva de totalidade e explicita no que consiste a especificidade que o Movimento reivindica: esta estaria relacionada à necessidade de se considerar, na formulação de políticas públicas, a população que vive no campo, seus sujeitos, seus modos de vida, sua realidade, sua prática social. De qualquer modo, os aspectos destas concepções educacionais presentes no Movimento por Uma Educação do Campo que são materializados na política educacional alinham-se a um projeto conservador que fragmenta a educação destinada à classe trabalhadora em modalidades específicas.

Compreendemos o que diz Caldart (2009) a respeito da complexidade e das contradições da história ainda recente do Movimento por uma Educação do Campo. Concordamos com a autora quando afirma que os verdadeiros protagonistas do Movimento são os sujeitos do campo e que este protagonismo, muitas vezes, pode ser deslocado para outros sujeitos. É importante esclarecer que nossa discussão tem como horizonte o fato de que o Movimento é muito mais amplo que os documentos que estabelecem as referências e diretrizes para a política educacional voltada para o campo. Entretanto, as concepções educacionais que se tornaram política pública foram aquelas presentes nos cadernos Por uma Educação Básica do Campo, quais sejam, as que mais interessam ao Estado capitalista. Nossa crítica se dirige a estas concepções, que foram outrora concepções do Movimento, mesmo que alguns de seus intelectuais estejam, no momento presente, aproximando-se da teoria marxista. A relevância deste embate, desta discussão e de uma visão questionadora a respeito destas concepções está longe de se manter apenas no plano teórico. Afinal, compartilhamos da concepção dialética de mundo e da tese marxista segundo a qual teoria e prática não podem ser consideradas separadamente. Portanto, discutir concepções teóricas, sejam elas pedagógicas ou educacionais em sentido mais amplo, é importante para definirmos o que direcionará tanto a estratégia quanto as táticas de luta da classe trabalhadora. Além disso, as questões por nós levantadas se dirigem à educação que o Estado tem destinado à população rural, portanto, tomamos como análise dois dos principais documentos oficiais sobre as políticas educacionais para o campo.

No livro, Educação para o campo em discussão: reflexões sobre o Programa Escola Ativa, Bezerra Neto e Bezerra (2011), ao analisarem o projeto de educação do campo no Brasil, sinalizam que a luta pela educação do campo se tornou uma luta possível devido às próprias mudanças no projeto capitalista para a educação, no qual o 
analfabetismo na classe trabalhadora se tornou um entrave para o desenvolvimento dos projetos capitalistas (BEZERRA NETO e BEZERRA, 2011, p. 9).

Segundo os autores, na atual conjuntura, o interesse por propostas de educação do campo deve ser atribuído a três fatores: a tecnologia no campo aplicada à monocultura exige um novo tipo de trabalhador rural, sendo que a enxada passa a não ser mais o principal instrumento de trabalho; a pressão dos movimentos sociais que atuam pela formação dos assentados em áreas de reforma agrária; e devido à orientação dos organismos internacionais que condicionam os empréstimos econômicos aos países da América Latina à erradicação do analfabetismo e aos investimentos na Educação Básica. Assim, para os autores, a educação do campo em sua gênese está mais atrelada ao capital internacional que à classe trabalhadora; fato que não impossibilita que a classe trabalhadora possa repensar e se beneficiar com as propostas de educação do campo (BEZERRA NETO e BEZERRA, 2011).

Considerando os aspectos inerentes à luta classes no sistema educacional, e, especialmente, no interior da escola, reconhecemos que a escolarização tem papel essencial na formação dos trabalhadores, de modo que as instituições escolares, desde a educação infantil ao ensino superior, estão impregnadas de um conjunto de práticas e de formas de pensamento que reproduzem o cotidiano alienado da sociedade capitalista contemporânea (DUARTE, 2006, p. 97). E, é por estas veredas que o capital, por intermédio da escola, conduz a "educação" do futuro trabalhador. Bem, esta "educação" não deve ser entendida no sentido pleno do termo, que remete à formação humana integral, omnilateral - ou nos dizeres de Marx (1983) combinação de instrução, ginástica e trabalho produtivo-; trata-se, como sabemos, de uma formação voltada para o mercado de trabalho, que permite aos trabalhadores operarem, como pouco treinamento, máquinas cada vez mais modernas, usarem os novos insumos e defensivos agrícolas, ou, ainda, adaptarem-se à nova organização do trabalho.

Diante das novas exigências do setor produtivo, base material da sociedade, os projetos de educação têm sido reformulados e, posteriormente, expandidos; pois o século XXI requer que as crianças e os jovens da atualidade se preparem e se qualifiquem, a fim de se tornarem os "cidadãos-trabalhadores" do futuro. Em suma, o capital em seu estágio atual requer um projeto de educação que, principalmente, atenda às exigências dos novos postos de trabalho.

Faz-se necessário, ainda, problematizarmos a armadilha ideológica existente na reivindicação da especificidade na educação do aluno do campo, pois se a formação oferecida à criança da classe trabalhadora além de "básica", ou seja, voltada para a qualificação para o mundo do trabalho, se constituir em uma formação específica, fragmentada, com adaptações curriculares que contemplem o cotidiano, a vida e o trabalho no campo, a escola da classe trabalhadora "se empobrece", visto que abre mão de garantir a criança seu direito de apropriar-se do conhecimento formal.

A luta dos movimentos sociais do campo por educação tem resultado em construção de concepções de "educação do campo" e de políticas públicas voltadas especificamente para o "campo". As Referências para Uma Política Nacional de Educação do Campo estão em um documento do MEC datado de 2003 que estabelece subsídios para formulação destas políticas em âmbito nacional "respaldadas em diagnósticos do setor educacional, nos interesses e anseios dos sujeitos que vivem no campo e nas demandas dos 
movimentos sociais." (BRASIL, 2003, p. 5). Este documento parte de dois fundamentos básicos da educação do campo, que são:

I. A superação da dicotomia entre rural e urbano - não é preciso destituir a cidade para o campo existir, nem vice-versa. O campo e a cidade são dois espaços que possuem lógicas e tempo próprios de produção cultural, ambos com seus valores. Não existe um espaço melhor ou pior, existem espaços diferentes que co-existem, pois muito do que é produzido na cidade está presente no campo e vice-versa (BRASIL, 2003, p. 32)

II. Relações de pertença diferenciados e abertos para o mundo O sentimento de pertença é o que vai criar o mundo para que os sujeitos possam existir, se os sujeitos não se sentirem pertencentes ao campo ou à cidade não podem desenvolver suas competências, seus valores. Pertencer significa se reconhecer como integrante de uma comunidade e é este sentimento que faz com que possam defender as suas idéias, recriar formas de convivência e transmitir valores de geração a geração. São esses, sentimentos fundamentais na formação da identidade com o campo ou com a cidade (BRASIL, 2003, p. 32)

O primeiro fundamento nos mostra que as referências para políticas educacionais para o campo partem do pressuposto de que existe uma dicotomia entre rural e urbano. Esta dicotomia está baseada na ideia de uma "clara dominação do urbano sobre o rural, na sua lógica e em seus valores" no plano das relações sociais (KOLLING, et al. 1999, p. 19). Segundo esta ideia, a falta de acesso da população rural a serviços sociais básicos seria consequência da visão de que o urbano é o ambiente moderno e o caminho natural para o progresso, enquanto o rural seria o ambiente atrasado e que estaria fadado à extinção (como mostrariam as taxas de urbanização cada vez maiores para o Brasil). Esta visão do campo como um lugar atrasado fomentaria um preconceito contra o habitante do campo, visto como ignorante, "caipira", "jeca-tatu", e outros adjetivos pejorativos. Assim, se o rural está desaparecendo, já que o caminho natural do progresso seria a cidade, o que justificaria a atenção do poder público à educação em áreas rurais? (ARROYO, FERNANDES, 1999; KOLLING, et al., 2002).

Este preconceito contra o homem do campo destinaria às áreas rurais uma educação abandonada e minimalista, que pretenderia uma imposição do modelo de escola urbano na escola rural (ARROYO, FERNANDES, 1999). Por isso seria importante superar a dicotomia entre rural e urbano nas políticas educacionais e destinar à escola do campo uma educação condizente com o ambiente no qual ela pertence. De acordo com as Referências:

Uma política de educação do campo precisa conceber que a cidade não é superior ao campo, e, a partir dessa compreensão, criar relações de horizontalidade e não de verticalidade entre campo e cidade, nas formas de poder, de gestão das políticas, de produção econômica e de conhecimento (BRASIL, 2003, p. 33).

Este fundamento parte da compreensão de que a contradição estaria entre cidade e campo ou entre rural e urbano e não entre capital e trabalho. A educação minimalista das 
escolas rurais seria resultado do preconceito contra o rural e não resultado da lógica de acumulação capitalista.

O segundo fundamento parte da necessidade de criar vínculos de pertença ao campo, relacionada à construção da identidade do sujeito do campo. Ou seja, seria objetivo da educação do campo fixar o sujeito à terra. Fazendo uma ligação com o pensamento de Bezerra Neto (2010, p. 151-152), podemos afirmar que as bases epistemológicas das concepções de educação do campo expostas até aqui têm como ponto de partida o entendimento de que o mundo rural e o mundo urbano são diferentes, como se não fossem ambos parte de uma mesma totalidade. Além disso, uma educação que tenha como um de seus objetivos fixar o homem à terra guarda semelhança ao que defendia o ruralismo pedagógico do início do século XX e aponta a educação, e não as bases materiais da sociedade, aquela que conduziria, em última instância, a possibilidade de o habitante rural continuar produzindo no campo ou ter que migrar para a cidade.

As concepções que fundamentam as políticas educacionais para o campo centralizam-se na necessidade de construção e resgate de culturas e valores que sejam específicos do campo. Mesmo que esta especificidade seja colocada em "relação com o que a cidade produz", como no trecho abaixo, ainda há o pressuposto de que o que destitui os valores e a cultura do campo é a imposição da "lógica urbana".

A educação do campo produz cultura a partir das especificidades do campo, mas sem perder de vista a sua inter-relação com o que a cidade produz. Essa idéia confronta a lógica distorcida colocada por uma concepção de campo subjugada à lógica urbana e destituidora do sentido do campo como espaço vivido (BRASIL, 2003, p. 33).

Não se menciona o fato de que, especialmente a partir da década de 1980, o avanço capitalista nas áreas rurais, que intensificou a concentração de terras, "flexibilizou" e precarizou as relações de trabalho, empurrou parcelas cada vez maiores da população rural para a cidade, para a pobreza, para a miséria e para o movimento social (OLIVEIRA, 2001, p. 187-188).

Mais adiante, no documento sobre as Referências afirma-se que "a educação do campo deve compreender que os sujeitos possuem história, participam de lutas sociais, sonham, tem nomes e rostos, lembranças, gêneros e etnias diferenciadas" (BRASIL, 2003, p. 34). Portanto, o currículo que deve vigorar na escola do campo:

não pode deixar ausentes as discussões sobre os direitos humanos, as questões de raça, gênero, etnia, a produção de sementes, o patenteamento das matrizes tecnológicas e das inovações na agricultura, a justiça social e a paz (BRASIL, 2003, p. 34)

O documento que traz as Diretrizes Operacionais para a Educação Básica nas Escolas do Campo (BRASIL, 2002), em seu artigo quinto, diz:

As propostas pedagógicas das escolas do campo, respeitadas as diferenças e o direito à igualdade e cumprindo imediata e plenamente o estabelecido nos artigos 23, 26 e 28 da Lei 9.394, de 1996, contemplarão a diversidade do campo em todos os seus aspectos: sociais, culturais, políticos, econômicos, de gênero, geração e etnia. 
Não podemos deixar de notar que estas concepções que norteiam políticas públicas para a população trabalhadora rural estão embasadas em correntes pós-modernas. O pósmodernismo na educação, ao negar a totalidade, caminha em direção ao relativismo epistemológico e cultural, sendo que este último, no limite, acarreta a fragmentação e até mesmo a insolvência do currículo (DUARTE, 2008, p. 2).

Com efeito, esta modalidade educacional (a educação do campo) sugere um currículo específico, ou, uma adaptação curricular que contemple a cultura, os processos de produção e as técnicas de trabalho do rural brasileiro, reivindica uma educação "diferente" por considerar que o aluno do campo é diferente. Seguindo esta concepção, existem então "diferentes" realidades, e para cada uma destas há necessidade de um projeto de educação específico. Este discurso novidadeiro - que sugere novos métodos, novas fontes e novos problemas - busca analisar e valorizar o micro, o fragmentário, o cotidiano, o singular, o imaginário (LOMBARDI, 2011). E esta é mais uma estratégia do capital para escamotear as desigualdades de classe, visto que se atribui os termos "específico" ou "diferente" ao que é desigual, e assim, descaracteriza-se a luta dos trabalhadores para ter acesso ao que de melhor a humanidade elabora; visto que o "diferente" que cabe à classe trabalhadora, em termos educacionais, é o elementar, o básico, o imediato e pragmático.

No projeto hegemônico de educação, o construtivismo ganha destaque entre as concepções pedagógicas. Arce (2000) ao discorrer a respeito do construtivismo na conjuntura neoliberal sinaliza os riscos comuns a esta teoria.

O construtivismo apresenta de forma exemplar a função máxima que a educação pode exercer neste contexto: desenvolver cada vez mais a capacidade adaptativa para poderem sobreviver. A escola empobrece-se cada vez mais; o conhecimento acumulado pela humanidade torna-se algo para poucos; o senso comum invade a escola disfarçado de "sabedoria popular" (sabedoria esta cheia de crendices mistificadoras e retrógradas), e o professor deixa de ser um intelectual para se tronar um mero "técnico" ou "acompanhante" do processo de construção do indivíduo. [...] (ARCE, 2000, p. 52).

Alertamos para o risco de as concepções de educação do campo aproximarem-se da concepção construtivista de educação, à medida que se destina à população rural uma educação diferenciada; em que se hiper valoriza o imediato, o cotidiano, os saberes que o educando já possui e coloca-se em segundo plano o conhecimento produzido socialmente e acumulado historicamente. Há contundentes críticas a esta concepção de educação, afirmase que a defesa da especificidade da educação do campo, e de seus pressupostos filosóficos-pedagógicos, baseiam-se em projetos que se aproximam aos ideais burgueses de educação, cujas bases designam diferenciados níveis e modalidades educacionais entre as diferentes camadas da população. O que se verifica na atualidade é um modelo de educação cada vez mais específico para determinadas parcelas da sociedade.

A fragmentação da educação destinada aos trabalhadores em modalidades específicas acarreta um grave risco à sua organização enquanto classe. Nas palavras de Arce (2000, p. 52), "fragmenta-se para destruir qualquer possibilidade de união e mudança no quadro político, econômico e social". A educação específica também é uma forma de limitar o acesso ao conhecimento sistematizado construído historicamente pela 
humanidade. Nesta perspectiva perde-se de vista que o conhecimento científico, artístico e a cultura em suas formas mais universais e desenvolvidas são o que humaniza o indivíduo e que o faz ter uma relação consciente com o gênero humano (DUARTE, 2013).

A atual concepção burguesa hegemônica de educação, o construtivismo, aponta a necessidade de a prática educativa partir do interesse do aluno, colocando este no centro do processo educativo, de modo que suas escolhas devam ser consideradas, sendo que o papel do professor será apenas de um mediador, entre o aluno/criança e o conhecimento.

A pedagogia burguesa, para Saviani (2012, p. 79) concebe os alunos como indivíduos empíricos, ou seja, como "sujeitos singulares, que se distinguem uns dos outros pela sua originalidade, criatividade e autonomia". Por esse caminho a pedagogia moderna elimina a história e naturaliza as relações sociais, pois entende que os educandos podem se desenvolver simplesmente por suas disposições internas, por suas capacidades naturais, inscritas em seu código genético (SAVIANI, 2012, p. 79). Nesta concepção, a criança do campo é colocada no centro do processo educativo e toda ação escolar deve ser desencadeada a partir dos interesses deste aluno. Sublinha-se também que este é entendido como diferente, ou portador de especificidades, pelo fato de residir no meio rural; desconsidera-se o fato deste aluno pertencer à classe trabalhadora (aqui nos referimos a todos os trabalhadores, isto é, todos aqueles que são obrigados a vender sua força de trabalho e não apenas os trabalhadores rurais) que tem sido privada do patrimônio cultural e científico historicamente elaborado pela humanidade.

Para Saviani (2012) esta concepção em nada favorece os interesses da classe trabalhadora e aponta para a concepção de aluno que uma pedagogia comprometida com a classe trabalhadora defende:

Daí, a grande importância de distinguir, na compreensão dos interesses dos alunos, entre o aluno empírico e o aluno concreto, firmando-se o princípio de que o entendimento aos interesses do aluno concreto. $\mathrm{O}$ aluno empírico pode querer determinadas coisas, pode ter interesses que não necessariamente correspondem aos interesses concretos. É nesse âmbito que se situa o problema do conhecimento sistematizado, que é produzido historicamente e integra o conjunto dos meios de produção. Esse conhecimento sistematizado, pode não ser do interesse do aluno empírico, ou seja, o aluno, em termos imediatos, pode não ter interesse no domínio desse conhecimento; mas ele corresponde diretamente aos interesses do aluno concreto, pois enquanto síntese das relações sociais, o aluno está situado numa sociedade que põe a exigência do domínio desse tipo de conhecimento. E é, sem dúvida, tarefa precípua da escola viabilizar o acesso a esse tipo de saber (SAVIANI, 2012, p. 80).

O aluno empírico é chamado de "aluno em termos imediatos" pelo autor porque permanece preso à imediatez do cotidiano e ao senso comum. Não há, na perspectiva da pedagogia hegemônica, a possibilidade deste aluno superar a visão cotidiana de mundo, pois, se ele só deve aprender o que é de seu interesse imediato, não fará parte de sua educação o acesso a formas superiores de conhecimento, como ciência e cultura em suas formas mais desenvolvidas.

Já o aluno concreto, como síntese de relações sociais, é concebido como uma "unidade na diversidade". O que é do interesse deste aluno diz respeito às condições em 
que ele se encontra e não as que ele escolheu. Assim como a geração atual não escolhe os meios e as relações que herda da geração anterior, a sua criatividade não é absoluta, mas existe. A criatividade de uma geração se expressa na forma como ela assimila estas relações e as transforma (SAVIANI, 2012, p. 79). E as condições em que se encontram o aluno do campo são aquelas descritas por Oliveira (2001): um contexto de intensa exploração do trabalho, unida a uma intensa concentração de terras, formas brutais de violência e migração forçada.

No texto A formação do "cidadão-trabalhador": educação e cidadania no contexto do "novo industrialismo", Andrade (2008) aponta que a escolarização da classe trabalhadora, nas últimas décadas, vem sendo discutida por instâncias representativas empresariais, e buscam formular propostas educacionais que desenvolvam no futuro "cidadão-trabalhador" o perfil comportamental e os requisitos cognitivos mais adequados para o patamar de produção requerido nos novos tempos. Para o autor, existe um entendimento de que as mudanças nas bases produtivas da sociedade brasileira impõem, para obter competitividade por parte do setor industrial brasileiro, a elevação do nível de escolaridade formal da força de trabalho, tanto existente quanto vindoura (ANDRADE, 2008, p. 61).

Andrade (2008) sinaliza que desde a década de 1990 importantes instituições organizativas empresariais, como o Instituto Euvaldo Lodi (IEL), vem discutindo e produzindo documentos que tratam da necessidade de adequação da educação aos novos tempos; tais documentos reforçam a relevância do acesso do futuro "cidadão-trabalhador" à escola, bem como o imperativo de mudança da cultura escolar que deve acompanhar a cultura do aparelho produtivo, de modo a atuar disseminando os valores e atitudes como competitividade, qualidade e produtividade, relativos a uma "nova ordem". Segundo o autor

Trata-se, portanto, de um esforço no sentido da "educação" do conjunto da população relativamente aos valores inerentes a este novo industrialismo contemporâneo, visando criar uma ampla base humana adequada às exigências do desenvolvimento capitalista em nosso país. A tarefa que se coloca para os empresários aí é não só a (con)formação da força de trabalho do presente, como também do futuro [...] (ANDRADE, 2008, p. 67).

No referido estudo, o autor, reportou-se a década de 1990, no entanto nos anos 2000 podemos destacar outros grupos empresariais que formulam e desenvolvem propostas educacionais, tais como Fundação Telefônica, Fundação Ford e FEAC e, no contexto da educação do campo podemos citar as mais recentes investidas do capital, como as propostas educacionais desenvolvidas pelo agronegócio brasileiro que tem adotado o Sistema SESI de ensino ou propostas de escolas complementar ou informal.

É neste sentido que a influência do construtivismo e a reivindicação de currículos específicos para a realidade do campo não representam avanços, em termos políticos e pedagógicos, para a formação da criança do campo; esta proposta educacional fora formulada pelos dirigentes para fortalecer a classe dirigente e manter o status quo.

Entende-se que a concepção de educação do campo e seus movimentos de luta trazem em si grandes paradoxos, pois ao mesmo tempo em que busca subverter a ordem política e econômica vigente, rompe com a visão de totalidade ao atribuir à educação a 
função de redentora dos males sociais e ao admitir a existência de um homem do campo e um homem da cidade, uma mulher do campo uma da cidade, quando não uma criança do campo e uma da cidade (BEZERRA NETO, 2010, p.152).

\section{A formação da classe trabalhadora e o ensino do campo}

Para autores como Bezerra Neto e Bezerra (2011), Cassin et al (2011), Duarte (2012) e Andrade (2008), a formação atualmente oferecida às crianças oriundas da classe trabalhadora é uma formação que almeja atender a demanda do mercado de trabalho capitalista, visto que não se verifica um projeto de formação humana voltado ao desenvolvimento amplo, omnilateral, do aluno da escola pública; com efeito, por vezes, estes são privados de conhecimentos apurados em Artes, Ciências Naturais (química, física e biologia), Ciências Exatas etc. (DUARTE, 2012). É reservado à criança pertencente à classe trabalhadora, o que de melhor há em educação para o mercado de trabalho, com especial destaque nos conhecimentos básicos para atividades laborativas na indústria e no comércio de bens e serviços; ou seja, em termos de formação humana, lhe é reservada a educação mais precarizada e unilateral possível - visto que prioriza o processo formativo voltado para o trabalho alienado, atividades geradoras de mais-valia, isto em detrimento de uma concepção de formação humana integral que objetiva o desenvolvimento máximo das habilidades humanas.

Os projetos de educação do capital se sustentam, e renovam, devido à própria necessidade desse sistema econômico de perpetuar as desigualdades de classe, nestas circunstâncias priva-se a criança da classe trabalhadora do conhecimento aprofundado, transmitindo-lhes apenas saberes e em doses homeopáticas, de modo a atrofiar as possibilidades de que tais crianças se apropriem de um saber que lhes possibilitem a subversão da ordem burguesa (SAVIANI, 2012).

E é no sentido de atender às demandas do sistema capitalista que a atual concepção de educação do campo se coloca; haja vista que defende uma educação "diferente", ou melhor, específica para o aluno do campo. Esta concepção de uma educação específica para campo é afirmada em documentos oficiais que norteiam políticas públicas.

Em uma análise crítica pode-se apreender que as diferentes concepções de educação para o campo, gestadas nos séculos XX e XXI, que por vezes aparentam, ou se apresentam, como antagônicas entre si e com o projeto de educação do capital, são meras adequações de um projeto de educação mais amplo, isto devido às próprias reestruturações da sociedade capitalista. Faz-se necessário, portanto, reafirmar a necessidade de uma concepção contra hegemônica de sociedade, educação, homem, criança, aluno. E esta concepção se encontra expressas nos escritos de Marx e Engels, na vasta produção dos pedagogos russos (Makarenko, Pistrak, Krupskaja etc.) e de autores marxistas contemporâneos.

Sublinha-se que para compreender a escola do campo contemporânea, e seu respectivo projeto de educação, temos que de compreender os processos produtivos do sistema capitalista, visto que os processos educativos e os processos produtivos mantém relação intrínseca e remetem à organização da materialidade e objetivação do trabalho; à luta de classes e à disputa de projetos históricos entre a classe trabalhadora e a burguesia. No que concerne à relação que se estabelece entre processos produtivos e a educação, Lombardi (2011) elucida: 
A tese é simples, até mesmo óbvia para o marxismo, qual seja: que a educação (e o ensino) é determinada, em última instância, pelo modo de produção da vida material; isto é, pela forma como os homens produzem sua vida material, bem como as relações aí implicadas, quais sejam, as relações de produção e as forças produtivas são fundamentais para apreender o modo como os homens vivem, pensam e transmitem as idéias e os conhecimentos que têm sobre a vida e sobre a realidade natural social (LOMBARDI, 2011, p. 12).

Deste modo, as mudanças na concepção e na forma de organização da educação em dada sociedade, sempre acompanham as mudanças estruturais da forma de organização do modo de produção. Neste sentido, para manter o status quo - a desigualdade entre a classe trabalhadora e classe proprietária dos meios de produção- o modo capitalista de produção estruturou um sistema capitalista de educação, que tem se consolidado no sentido de validar os processos econômicos vigentes, atua de modo a naturalizar as desigualdades sociais, com discurso de respeito às diferenças.

Em suma, criam-se, então, dois projetos de escola, a saber: um para classe burguesa que se desenvolve no sentido de formar os dirigentes da sociedade; e outro que desenvolve uma educação elementar, uma formação mínima voltada para a lógica de mercado do capitalismo, que busca instrumentar a classe trabalhadora para o mundo do trabalho.

\section{Referências}

ANDRADE, Flávio Anício. A formação do "cidadão-trabalhador": educação e cidadania no contexto do "novo industrialismo". In: Educação e Política no limiar do século XXI. Editora Autores associados, $2^{\mathrm{a}}$ edição, Coleção Educação Contemporânea. Campinas: 2008.

ARCE, Alessandra. A formação de professores sob a ótica construtivista, primeiras aproximações e alguns questionamento; $p$. 41-62 In: Sobre o construtivismo: contribuições para uma análise crítica. Newton Duarte (org.). Coleção Polêmicas do nosso tempo. Editora Autores Associados. Campinas: 2000.

; Lina, uma criança exemplar! Friedrich Froebel e a pedagogia dos jardins-de-infância. Revista Brasileira de Educação, n 20, maio/jun/jul/ago: 2002.

; MARTINS, Ligia Mácia. Quem tem medo de ensinar na educação infantil? Em defesa do ato de ensinar. Editora Alínea, Campinas: 2007.

ARROYO, Miguel Gonzales; FERNANDES, Bernardo Mançano. A educação básica e o movimento social do campo. Brasília: Articulação Nacional Por Uma Educação do Campo. Coleção Por Uma Educação Básica do Campo, n. 2. 1999.

BEZERRA NETO, Luiz. Educação do campo ou educação no campo. Revista HISTEDBR On-line, n. 38, p.150-168. Campinas: 2010. 
; BEZERRA, Maria Cristina dos Santos (organizadores). Educação para o campo em discussão: reflexões sobre o Programa Escola Ativa. $1^{\text {a }}$ edição: 2011.

BRASIL, Pacto Nacional de Alfabetização na Idade Certa. Brasília: 2012.

BRASIL. MEC. Diretrizes Operacionais para a Educação Básica nas Escolas do Campo. Resolução CNE/CEB, 1/abril/2002.

BRASIL. MEC. Referências para uma política nacional de educação do campo: caderno de subsídios. Brasília, DF: 2003. 40 p.

CALDART, Roseli Salete. Sobre a educação do Campo. In: Clarice dos Santos (Org.). Educação do Campo: Campo- políticas públicas -educação. Brasília: Incra; MDA, Brasil: 2008.

Trabalho, Educação e Saúde, Rio de Janeiro, v. 7, n.1, p. 35-64, mar/jun. 2009.

DI PIERRO, Maria Clara; ANDRADE, Marcia Regina. Escolarização em assentamentos no estado de São Paulo: uma análise da Pesquisa Nacional de Educação na reforma Agrária 2004. Revista Brasileira de Educação, v. 14, n 41, maio/ago: 2009.

DUARTE, Newton. Sobre o construtivismo: contribuições para uma análise crítica. Coleção Polêmicas do nosso tempo. Editora Autores Associados. Campinas: 2000.

; A pesquisa e a formação de intelectuais críticos na Pós-graduação em Educação. Revista Perspectiva, v. 24, n.1, p. 89-110, jan/jun. 2006. Florianópolis: 2006.

pedagogias $\quad$ relativistas. 2008. Disponível em http://www.nre.seed.pr.gov.br/cianorte/arquivos/File/PEDAGOGAS/CURRICULO/PELA SUPERACODOESFACELAMENTODOCURRICULOREALIZADOPELASPEDAGOGI ASRELATIVISTASNewtonDuarte.pdf> Acessado em julho/2013.

; Lukács e Saviani: a ontologia do ser social e a pedagogia históricocrítica. In: SAVIANI, Dermeval; DUARTE, Newton (Orgs.); Pedagogia histórico-critica e luta de classes na educação escolar. editora Autores associados, p. 37-57. Campinas: 2012.

2013. $254 \mathrm{p}$.

A individualidade para si. 3 ed. Campinas: Autores Associados,

HIDALGO, Angela Maria; MELLO, Cláudio José de Almeida. Reflexões sobre as diretrizes curriculares para a educação do campo do Paraná: pragmatismo, literatura e engajamento. Revista Ibero-americana de Educação, p. 1-13, n. 59/3, 15 jul. 2012. 
IANISKI, Gicéli Maria. A criança e seu espaço na sociedade contemporânea. IX Congresso Nacional de Educação - EDUCERE; III Encontro Sul Brasileiro de Psicopedagogia - PUCPR. UniCentro: 2009.

KOLLING, Edgar Jorge; CERIOLI, Paulo Ricardo; CALDART, Roseli Salete. Educação do campo: identidade e políticas públicas. Brasília: Articulação nacional Por Uma Educação do Campo. Coleção Por Uma Educação do Campo, n. 4. 2002.

KOLLING, Edgar Jorge; NERY, Irmão Israel José; MOLINA, Mônica Castagna. Por uma educação básica do campo (memória). Brasília: Articulação nacional Por Uma Educação do Campo. Coleção Por Uma Educação do Campo, n. 1. 1999.

LOMBARDI, José Claudinei. Educação e ensino na obra de Marx e Engels. Editora Alínea, Campinas: 2011.

MARTINS, Lígia Márcia. As aparências enganam: divergências entre o materialismo histórico dialético e as abordagens qualitativas de pesquisa. Grupo de Trabalho: Filosofia da Educação; Núcleo de Estudos e Pesquisa em Educação Infantil (NEPEI), Unesp: 2009.

; PASQUALINI, Juliana Campregher. A Educação Infantil em busca de identidade: análise crítica do binômio "cuidar-educar" e da perspectiva antiescolar em Educação Infantil. Revista Psicologia da Educação, $n^{\circ} 27,2^{\circ}$ semestre, PP.71100. São Paulo: 2008.

MARX, Karl. Manuscritos Económico-Filosóficos. Tradução Artur Morão, Editora Edições 70, Lisboa: 1963.

; O Capital. Edição resumida por Julian Borchardt, tradução de Ronaldo Alves Schmidt, $5^{\text {a }}$ edição, Biblioteca de Ciências Sociais; Editora Zahar, Rio de Janeiro: 1978.

; Textos sobre educação e ensino. Editora Moraes. São Paulo: 1983.

; ENGELS, Friedrich. La ideologia alemana. Montevideo: Pueblos Unidos;

Barcelona: 1974.

MEC. Referência para uma política nacional de educação do campo: caderno de subsídio/coordenação: RAMOS, Marise N., MOREIRA, Telma M. SANTOS, Clarice A. S. - Brasília: Secretaria de Educação Média e Tecnológica, Grupo Permanente de Trabalho de Educação do Campo. Brasília: 2004.

MOLINA, Mônica. A constitucionalidade e a justicialidade do direito à educação dos povos do campo. In: SANTOS, C. A. dos. Educação do campo, políticas públicas, educação. Brasília: INCRA/MDA/NEAD, 2008.

NEVES, Lúcia Maria Wanderley. Determinantes das mudanças no conteúdo das propostas educacionais no Brasil dos anos 90: período Itamar Franco. In: Educação e Política no limiar do século XXI. Editora Autores associados, $2^{\text {a }}$ edição, Coleção Educação Contemporânea. Campinas: 2008. 
OLIVEIRA, Ariovaldo. A longa marcha do campesinato brasileiro: movimentos sociais, conflitos e Reforma Agrária. Estudos Avançados, vol. 15, nº 43. 2001. P. 185-206.

PISTRAK, Mikhail. Fundamentos da escola do trabalho. Tradução de Daniel Aarão Reis Filho; Editora Expressão Popular, São Paulo: 2000.

SAVIANI, Demerval. O trabalho como princípio educativo frente às novas tecnologias. In: FERRETI, Celso J. et al (org.). Novas tecnologias, trabalho e educação: um debate multidisciplinar. Editora Vozes, Rio de Janeiro: 1996.

; Aspectos históricos e ontológicos da relação trabalho e educação, Revista Brasileira de Educação v. 12 n. 34 jan./abr: 2007.

; Escola e Democracia. Coleção Polêmicas do Nosso Tempo. Editora Autores Associados, Campinas: 2009.

; Marxismo, Educação e Pedagogia. In: SAVIANI, Dermeval; DUARTE, Newton (Orgs.); Pedagogia histórico-critica e luta de classes na educação escolar. editora Autores associados, p. 59-85. Campinas: 2012.

1 I Encontro Nacional de Educadores da Reforma Agrária - I ENERA em 1997 e I ConferênciaNacional por Uma Educação do Campo em 1998.

Recebido: $\quad$ janeiro-14 Aprovado: janeiro-15 